\title{
Patient safety in orthopedic surgery: prioritizing key areas of iatrogenic harm through an analysis of 48,095 incidents reported to a national database of errors
}

\author{
This article was published in the following Dove Press journal: \\ Drug, Healthcare and Patient Safety \\ 23 March 2013 \\ Number of times this article has been viewed
}

\author{
Sukhmeet S Panesarl \\ Andrew Carson-Stevens ${ }^{2}$ \\ Sarah A Salvilla' \\ Bhavesh Patel ${ }^{3}$ \\ Saqeb B Mirza ${ }^{4}$ \\ Bhupinder Mann ${ }^{5}$ \\ 'Centre for Population Health \\ Sciences, The University of \\ Edinburgh, Edinburgh, UK; ${ }^{2}$ Institute \\ of Primary Care and Public Health, \\ Cardiff University, Cardiff, UK; \\ ${ }^{3}$ National Patient Safety Agency, \\ London, UK; ${ }^{4}$ Department of \\ Trauma and Orthopaedic Surgery, \\ University Hospital Southampton \\ NHS Foundation Trust, Southampton \\ General Hospital, Southampton, \\ Hampshire, UK; ${ }^{5}$ Buckinghamshire \\ Healthcare NHS Trust, Stoke \\ Mandeville Hospital, Aylesbury, UK
}

Correspondence: Sukhmeet S Panesar Centre for Population Health Sciences, Doorway 3, Medical School Building, The University of Edinburgh, Teviot Place, Edinburgh EH8 9AG, UK

Tel +44 I3। 6508102

Email sukhmeet.panesar@

surgicalmatrix.com

\begin{abstract}
Background: With scientific and technological advances, the practice of orthopedic surgery has transformed the lives of millions worldwide. Such successes however have a downside; not only is the provision of comprehensive orthopedic care becoming a fiscal challenge to policy-makers and funders, concerns are also being raised about the extent of the associated iatrogenic harm. The National Reporting and Learning System (NRLS) in England and Wales is an underused resource which collects intelligence from reports about health care error.

Methods: Using methods akin to case-control methodology, we have identified a method of prioritizing the areas of a national database of errors that have the greatest propensity for harm. Our findings are presented using odds ratios (ORs) and $95 \%$ confidence intervals (CIs).

Results: The largest proportion of surgical patient safety incidents reported to the NRLS was from the trauma and orthopedics specialty, 48,095/163,595 (29.4\%). Of those, 14,482/48,095 (30.1\%) resulted in iatrogenic harm to the patient and 71/48,095 (0.15\%) resulted in death. The leading types of errors associated with harm involved the implementation of care and on-going monitoring (OR 5.94, 95\% CI 5.53, 6.38); self-harming behavior of patients in hospitals (OR $2.14,95 \%$ CI 1.45, 3.18); and infection control (OR 1.91, 95\% CI 1.69, 2.17). We analyze these data to quantify the extent and type of iatrogenic harm in the specialty, and make suggestions on the way forward.
\end{abstract}

Conclusion and level of evidence: Despite the limitations of such analyses, it is clear that there are many proven interventions which can improve patient safety and need to be implemented. Avoidable errors must be prevented, lest we be accused of contravening our fundamental duty of primum non nocere. This is a level III evidence-based study.

Keywords: orthopedic surgery, patient safety incident, iatrogenic harm, error

\section{Introduction}

The high frequency of medical errors and the associated disease burden resulting from iatrogenic harm remains an important challenge for health care systems globally. ${ }^{1}$ Almost a decade ago, the Institute of Medicine published a sentinel report, To Err is Human, which identified medical errors as a major challenge for public health. The report demonstrated the lethality of medical error and placed it on par with breast cancer or road traffic accidents; this analogy helped initiate efforts worldwide for addressing the threat to public health and safety. ${ }^{2}$

Surgical specialties have been a focus of opportunity as patient safety has developed its global enterprise. More than 234 million people require surgical treatment 
every year globally, and more than half of these treatments occur in developed countries. ${ }^{3}$ By the sheer numbers of procedures, both for emergency and elective problems, trauma and orthopedics as a specialty could be deemed more "risky," as partly evidenced by the fact that $20 \%$ of wrong-site surgery incidents occurred in the specialty in 2006-2007. ${ }^{4}$

In addition to additional mortality and morbidity, there are direct financial implications of unsafe care, and clinical negligence claims against the UK's National Health Service (NHS) demonstrate this. During the 2010/2011 financial year, negligence cost the NHS $£ 860$ million - a 9\% increase from the previous year. Trauma and orthopedics was the specialty with the highest number of clinical claims made. ${ }^{5}$

In the Institute for Medicine's follow up report, Crossing the Quality Chasm, ${ }^{6}$ the poor use of incident reporting systems was highlighted, since they are necessary to help inform actions to improve patient safety. Patient safety reporting systems (PSRSs) can aid understanding of the extent and nature of the problems that occur from errors. Such learning insights can lead to the development of interventions aimed at mitigating against errors; for example, the generation of alerts on the complications of a new drug; dissemination of lessons learned by health care organizations experiencing serious patient safety incidents (PSIs); and revelation of unrecognized trends in errors. ${ }^{7}$ National databases of errors have been created in many parts of the world, including the USA. ${ }^{8,9,10}$ These have offered important insights that have helped to shape national policy - for example, for demonstrating the risks of bone cement implantation syndrome associated with use of cement in hip fracture surgery, and the potential for IT-based interventions to reduce many cases of drug allergy related morbidity. ${ }^{11,12}$

The aim of this study was to understand the burden of harm in trauma and orthopedics using a cross-sectional methodology. As such, we wanted to ascertain what types of errors are associated with the greatest burden of harm in orthopedic patients.

\section{Methods}

The National Reporting and Learning System (NRLS) is a voluntary, national reporting system set up in 2003 for the NHS in England and Wales. It is the largest and most comprehensive reporting system in the world, with over 7 million PSIs recorded to date, with increases in the number of reports received each year since $2003 .{ }^{13}$ All staff working within the NHS can report incidents through their parent institution to ensure that local action can be taken when necessary. A representative from each parent institution is responsible for uploading records to the national database. In addition, health care staff, patients, and members of the public can report incidents independently through the NRLS website. $^{14}$

Each NRLS report refers to an unintended or unexpected incident that could have or did lead to harm for one or more patients receiving NHS-funded care. It also includes reports of incidents which reached the patient but did not lead to harm, and those which did not lead to harm because an incident was prevented from reaching the patient. Incidents are further stratified into different levels of harm. ${ }^{13}$ In order to integrate the wide variety of local safety management systems and software, the NRLS has 75 data fields, including incident categories at two levels, specialty and location of the incident, and free-text descriptions of the events. ${ }^{15}$ Each incident that is reported as leading to death or serious harm is reviewed individually by trained clinical staff and a range of outputs are produced to provide solutions to patient safety problems. These include one-page reports called Rapid Response Reports, quarterly data summaries, and topic-specific information on topics such as preventing inpatient falls in hospitals. There is constant consultation with subject-matter experts including professional organizations such as the Royal Colleges. NHS organizations also have deadlines imposed on them by which time they should have implemented any findings from those reports. ${ }^{13}$

Data from the NRLS database were analyzed for all incidents reported in the specialty of trauma and orthopedics from January 2009 to December 2009. The domains searched were "Acute/General Hospital" and "Trauma and Orthopedics" and limited to England.

There are 16 types of incident categories with further sub-divisions. Free text descriptions of all the PSIs were also abstracted. Harm was defined by user self-report as: no harm, low harm (minimal harm - patient[s] required extra observation or minor treatment), moderate harm (short term harm - patient[s] required further treatment or procedure), severe harm (permanent or long term harm), or death.

Our statistical approach involved the use of case-control methodology. The first case-control study revealed a link between tobacco smoking and lung cancer. ${ }^{16}$ We sought to extend this approach further, with the caveat that a deeper understanding of confounding factors would not be possible owing to the structure of the database. Our definition of a "case" was one where an error resulted in harm. The "controls" were defined as errors where no harm occurred or "near-misses." Errors were clustered into 15 discrete categories called "incident types." 15 We sought to evaluate 
the degree of association between different types of errors and the resultant harm to the patient.

Measures of relative effect express the outcome in one group relative to that in the other. Two common methods are used, the relative risk (RR) and the odds ratio (OR). The OR is the probability that a particular event will occur to the probability that it will not occur, and can be any number between zero and infinity. In gambling, the odds describe the ratio of the size of the potential winnings to the gambling stake; in health care, it is the ratio of the number of people with the event to the number without. Risk is the concept more familiar to patients and health professionals. Risk describes the probability with which a health outcome (usually an adverse event) will occur. Measures of relative effect express the outcome in one group relative to that in the other. Hence, the RR is the ratio of the risk of an event in the two groups whereas the OR is the ratio of the odds of an event.

For treatments that increase the chances of events, the OR will be larger than the risk ratio, so the tendency will be to misinterpret the findings in the form of an overestimation of treatment effect, especially when events are common (with, say, risks of events more than 20). For treatments that reduce the chances of events, the OR will be smaller than the risk ratio, so that again misinterpretation overestimates the effect of treatment. Furthermore, the RR is an easier concept to understand. ${ }^{17}$ A $2 \times 2$ design was constructed for each of the categories (Table 1).

\section{Results}

There were 48,095 PSIs from trauma and orthopedics incidents reported to the NRLS in 2009. Of those, $14,482 / 48,095(30.1 \%)$ resulted in iatrogenic harm to the patient, and 71/48,095 (0.15\%) resulted in death. There were 155 NHS trusts that reported data to the database. Aggregate frequencies of harm and examples of the freetext are shown in Table 2. Large proportions of harm were seen in the following categories of harm: patient accident $(\mathrm{n}=5639,11.72 \%)$, implementation of care and on-going monitoring/review $(n=2600,5.41 \%)$, treatment $(n=2091$,

Table I $2 \times 2$ table to calculate degree of association

\begin{tabular}{llll}
\hline & Harm & No harm & Total \\
\hline Category A & $\mathrm{a}$ & $\mathrm{b}$ & $\mathrm{a}+\mathrm{b}$ \\
All categories - category A & $\mathrm{c}$ & $\mathrm{d}$ & $\mathrm{c}+\mathrm{d}$ \\
Total & $\mathrm{a}+\mathrm{c}$ & $\mathrm{b}+\mathrm{d}$ & $\mathrm{a}+\mathrm{b}+\mathrm{c}+\mathrm{d}$ \\
\hline
\end{tabular}

Notes: OR = Odds of harm in orthopedic category A/Odds of harm across al orthopedic categories; $O R=(\mathrm{a} / \mathrm{b}) /(\mathrm{c} / \mathrm{d})$.

Abbreviation: OR, odds ratio.
$4.35 \%)$, medication $(n=744,1.55 \%)$, and access, admission, transfer, discharge (including missing patient) $(\mathrm{n}=606$, $1.26 \%$ ). Table 3 lists the proportion of harm exhibited by each category of error.

A breakdown of incidents according to the pre-defined categories is given in Figure 1. The five statistically significant areas of harm include implementation of care and ongoing monitoring/review; self-harming behavior; infection control incidents; other; and treatment/procedure.

\section{Discussion}

The areas of concern that we have highlighted in our study are well recognized within the specialty. The largest category of concern is "implementation of care and on-going monitoring/review" [OR $=2.55,95 \%$ CI 2.49, 2.62], and this is a recognized problem for the fragility of hip fractures. Uptake of best practice guidelines released by the UK Department of Health has been variable. ${ }^{18}$ Key components for delivery of its best practice agenda include a reduction in the delay to surgery and involvement of an orthogeriatrician in the care of patients. Different models of orthogeriatric care have been proposed with the aim of ensuring an integrated multidisciplinary team approach with evidence-based pathways. ${ }^{19}$ Overall, several tools are now available to mitigate harm associated with poor care of orthopedic patients; pre- and post-operative adjuncts such as better use of orthogeriatric services, ${ }^{19}$ early warning scores and trigger tools to prevent major catastrophes during the pre-, intra-, and post-operative phases of care, ${ }^{20}$ enhanced recovery protocols ${ }^{21}$ for the entire patient journey to ensure that best practice guidelines are adhered to, and intra-operative tools such as the World Health Organization surgical checklist. ${ }^{22}$

A second finding of interest was the greater propensity of self-harming behavior incidents on orthopedic wards. Several recommendations have been made which place the onus on clinical services to place priority for suicide prevention and monitoring, ${ }^{23}$ including a suicide prevention for hospital patients toolkit. ${ }^{24}$ Infection control incidents were also a domain of concern in our analyses [OR $=1.50$ $(95 \%$ CI 1.41, 1.61)], and health care associated infections are recognized to be the most frequent adverse event that threaten patients' safety, with a large burden of avoidable harm. ${ }^{25}$ Prevention of these infections occurs in the pre-, peri-, and post-operative phases. ${ }^{26}$

This is the first attempt to our knowledge of quantifying the burden of iatrogenic harm in the specialty of orthopedics and trauma using a PSRS. However, this is only a start and much more needs to be done, given concerns about the 


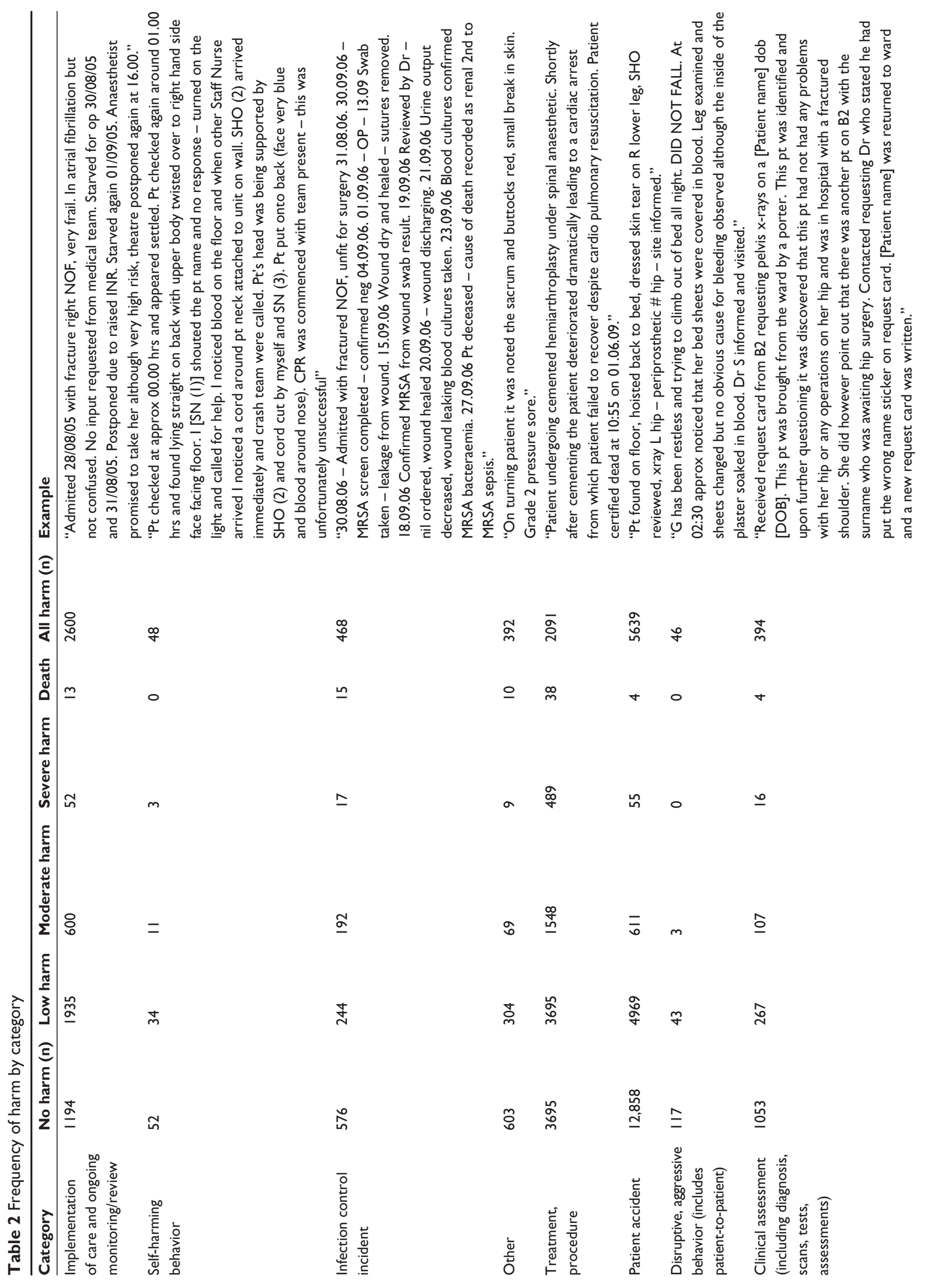




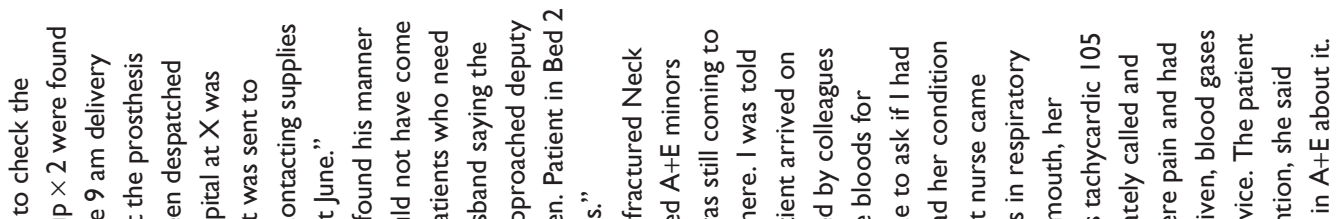

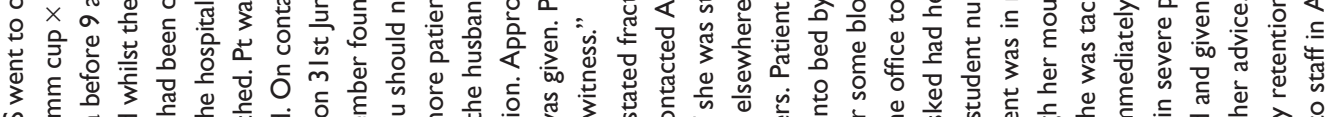

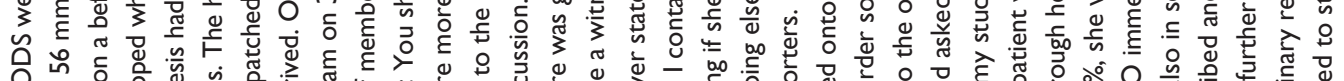

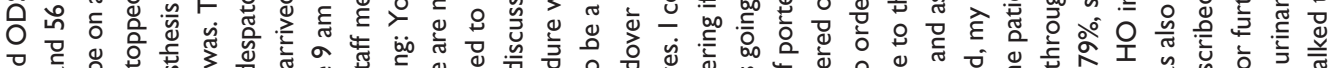

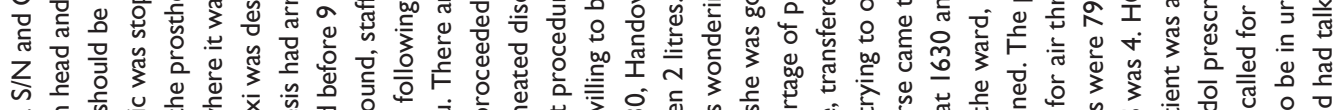

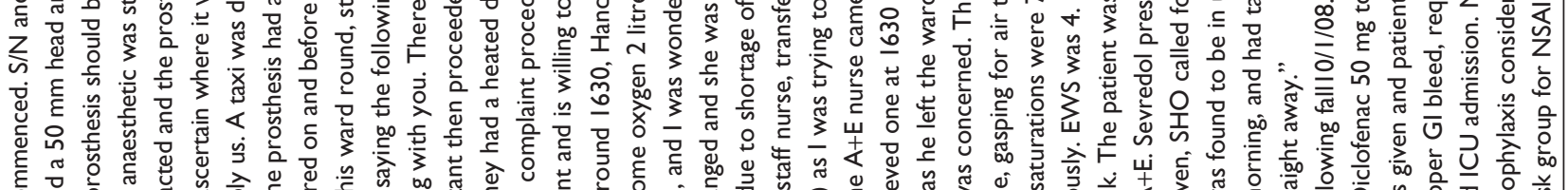

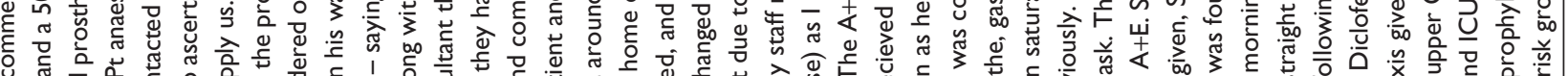

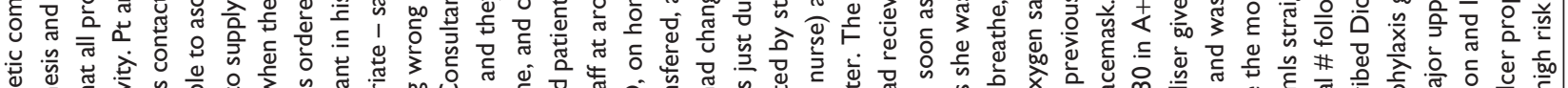

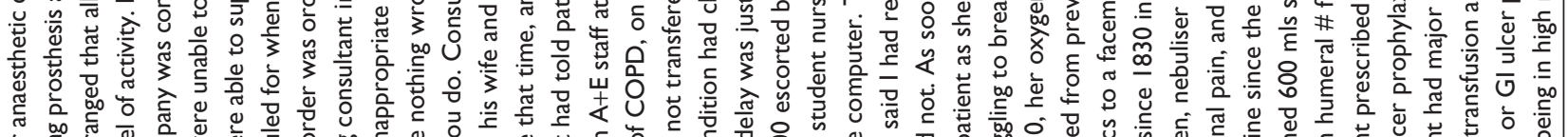

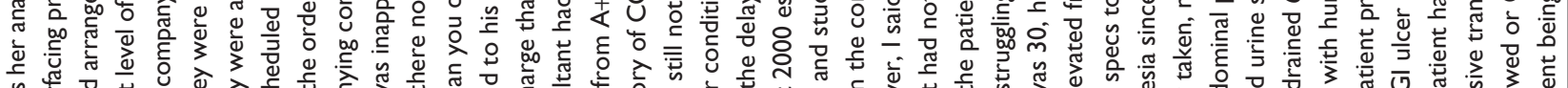

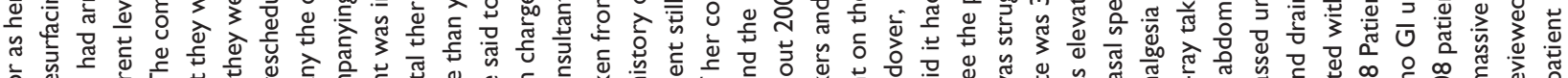

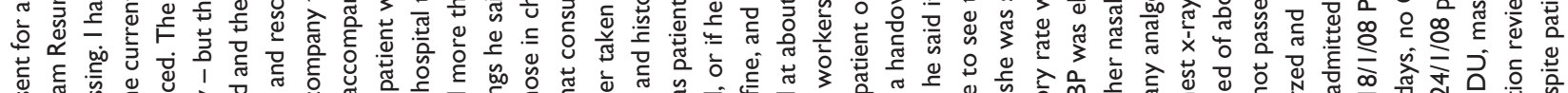

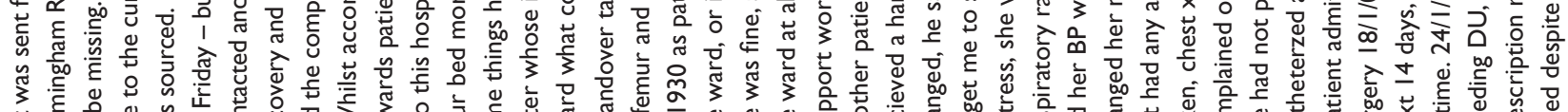

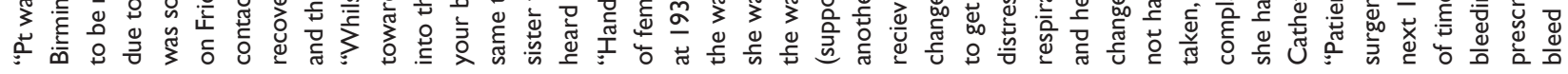

รู

$\sim$

0

ఫ

กิ

$\overline{\underline{9}}$

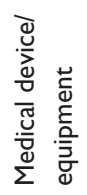

$\simeq$

:

$\pm$

느

$\stackrel{\infty}{\underline{ }}$

ริ

$\stackrel{\circ}{\frac{0}{4}}$

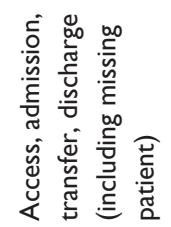

ถิ

함

q

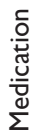




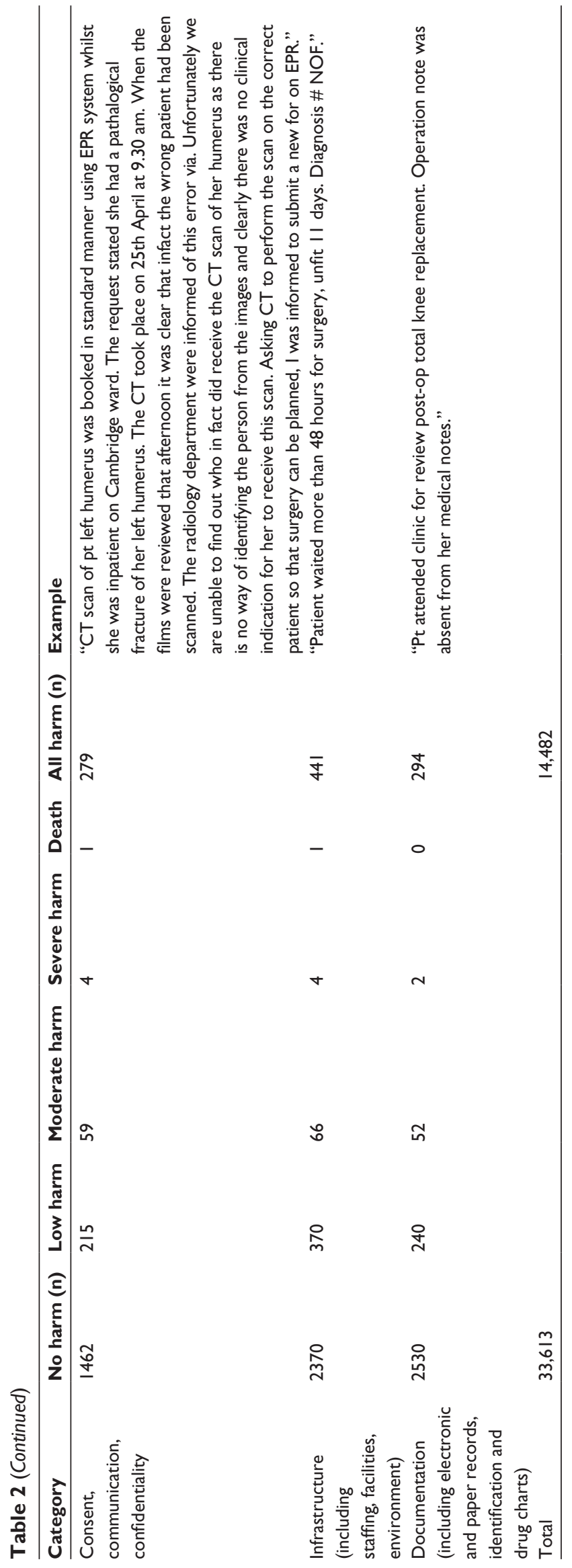

Table 3 Proportion of harmful incidents in each category

\begin{tabular}{|c|c|c|}
\hline Category & All harm & $\begin{array}{l}\text { Percentage of } \\
\text { all patient safety } \\
\text { incidents }(n=48,095)\end{array}$ \\
\hline Patient accident & 5639 & 11.72 \\
\hline $\begin{array}{l}\text { Implementation of care and } \\
\text { ongoing monitoring/review }\end{array}$ & 2600 & 5.41 \\
\hline Treatment, procedure & 2091 & 4.35 \\
\hline Medication & 744 & 1.55 \\
\hline $\begin{array}{l}\text { Access, admission, transfer, } \\
\text { discharge (including missing } \\
\text { patient) }\end{array}$ & 606 & 1.26 \\
\hline Infection control incident & 468 & 0.97 \\
\hline $\begin{array}{l}\text { Infrastructure (including staffing, } \\
\text { facilities, environment) }\end{array}$ & 441 & 0.92 \\
\hline Medical device/equipment & 423 & 0.88 \\
\hline $\begin{array}{l}\text { Clinical assessment } \\
\text { (including diagnosis, scans, } \\
\text { tests, assessments) }\end{array}$ & 394 & 0.82 \\
\hline Other & 392 & 0.82 \\
\hline $\begin{array}{l}\text { Documentation (including } \\
\text { electronic and paper records, } \\
\text { identification, and drug charts) }\end{array}$ & 294 & 0.61 \\
\hline $\begin{array}{l}\text { Consent, communication, } \\
\text { confidentiality }\end{array}$ & 279 & 0.58 \\
\hline Self-harming behavior & 48 & 0.10 \\
\hline $\begin{array}{l}\text { Disruptive, aggressive behavior } \\
\text { (includes patient-to-patient) }\end{array}$ & 46 & 0.10 \\
\hline $\begin{array}{l}\text { Patient abuse } \\
\text { (by staff/third party) }\end{array}$ & 17 & 0.04 \\
\hline Total & 14,482 & 30.11 \\
\hline
\end{tabular}

utility of databases to promote safety. An increased rate of reporting, whereas in itself could imply that the culture of patient safety is improving, on its own is of limited value. The National Patient Safety Agency had 158 incidents reported in 2003 and to date has over 7 million incidents reported to it. ${ }^{27,28}$ Paradoxically, despite the large number of incident reports received by the NRLS, reporting systems have been shown to detect only about $6 \%$ of adverse events found by a systematic review of records. ${ }^{29}$ Indeed, it has been argued that national reporting systems are of great importance at identifying rare events, but of limited use in analyzing trends or acting as measurements of patient safety. ${ }^{30}$ It is commendable that several solutions have been provided in the form of alerts and rapid responses. ${ }^{11}$ However, most of these solutions seem reactive. ${ }^{31}$ At present, the lesson from national PSRS is limited; some of the information is lost in translation. ${ }^{32}$ Local systems of risk management opt for root cause analyses to develop local solutions to mitigate against harm to the patient. National systems rely on patient safety experts methodically trawling through PSIs by severity and frequency, thereby leading to the production of quarterly 


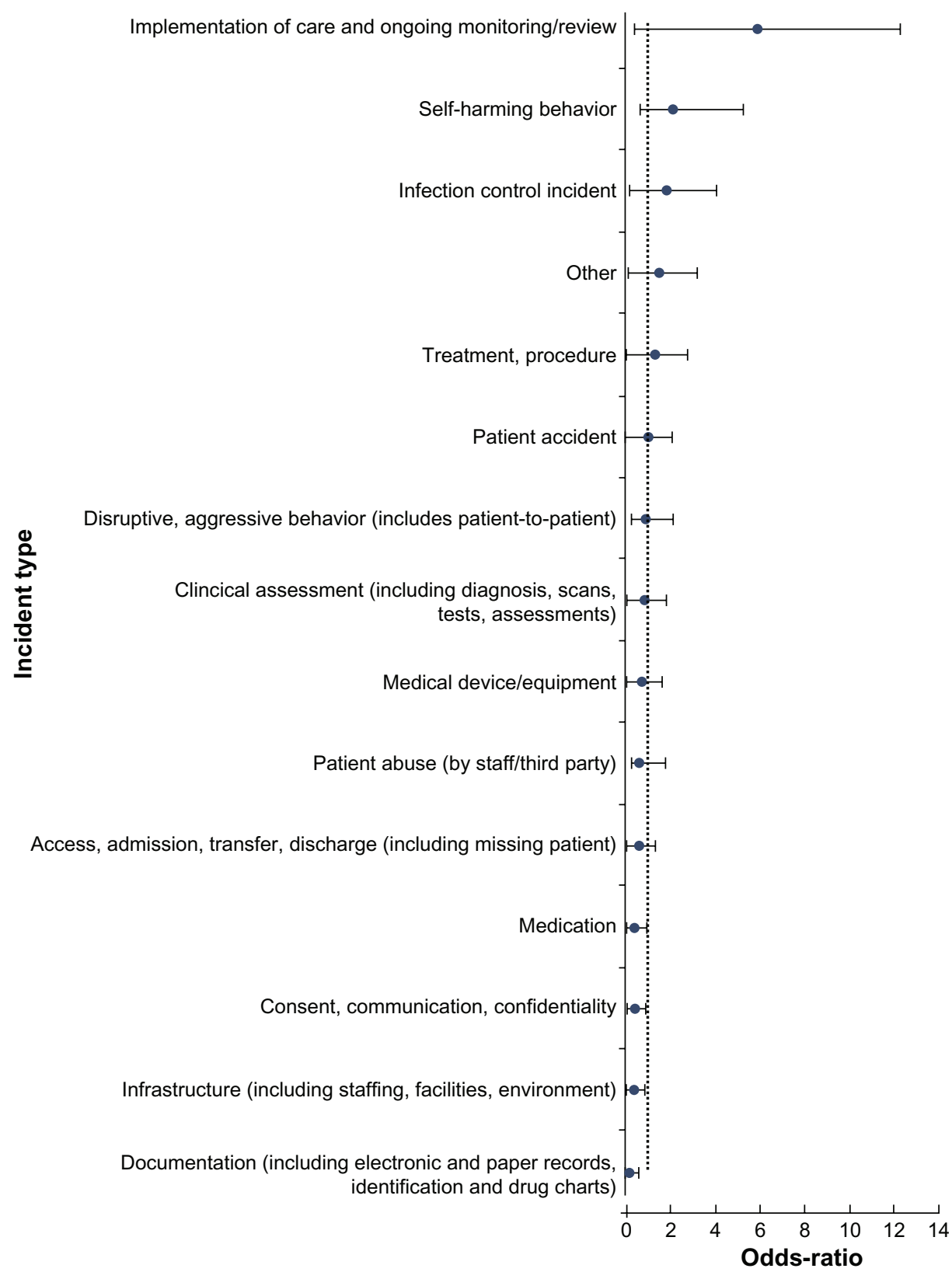

Figure I Odds ratios of different categories of harm.

reports, alerts, and rapid response solutions. ${ }^{14}$ Such analyses are time-consuming as the size of the PSRS increases and may be of limited value. There is a need for applied epidemiological tools to be created to allow clusters of harmful incidents to be identified, both by hospital and specialty. This may offer a true reporting and learning system which actively engages stakeholders in delivering error-free care for patients. Most commentators agree that the long term and sustainable solution lies in professional engagement and local efforts.

The gross under-reporting to PSRSs has been cited as their "Achilles heel" and, as such, their use is often limited to warning, communication, and detection of rare PSIs. ${ }^{30}$ Whilst this may be a valid criticism, it is clear that reporting is increasing as clinicians become more aware of the presence of PSRSs, and furthermore develop confidence that there will not be any personal repercussions to making reports. Also, one might argue that a vast majority of incidents result in no harm whatsoever, and it could create a false impression of over-reporting and the subsequent arguments of bureaucracy and misrepresentation of the situation. However, convincing clinicians of the usefulness of the data they contribute should in due course further increase the frequency and quality of reporting. It will also help specialties such as orthopedics 
to develop surveillance tools and easier methods of understanding highly error-prone situations to which ameliorative solutions must be provided. There are some limitations to our methods as they stretch the application of case-control methodology. Owing to missing data, we are unable to definitely assess the effect of causative factors for errors, including those such as age and experience of the doctor.

The number of orthopedic patients suffering preventable adverse events is high. This has been shown in non-UK settings as well; almost half of all members of the American Academy of Orthopaedic Surgeons, who agreed to a survey, reported that they had observed a medical error. ${ }^{33}$ Looking at the number of orthopedic surgery consultations in the NHS during 2008/2009, the crude proportion of these errors would appear to be small $(48,095 / 1,144,520,4.2 \%)$, but it is the absolute number that is key. ${ }^{34}$

Iatrogenic harm in trauma and orthopedic surgery is an important issue and we need a multi-pronged strategy to address it. In addition, to better study the problem by building research capacity in the area, we need to act on known and proven interventions for delivering safer care: better clinical leadership, promoting the use of patient safety indicators as part of quality accounts for orthopedic surgeons within hospitals, and to showcase examples of best practice that use quality improvement and patient safety metrics.

\section{Disclosure}

The authors report no conflicts of interest in this work.

\section{References}

1. Hurwitz B, Sheikh A, editors. Health Care Errors and Patient Safety. Oxford: Wiley Blackwell; 2009.

2. Kohn LT, Corrigan JM, Donaldson MS, editors. To Err Is Human: Building a Safer Health System. Washington: National Academy Press; 1999.

3. Weiser TG, Regenbogen SE, Thompson KD, et al. An estimation of the global volume of surgery: a modelling strategy based on available data. Lancet. 2008;372(9633):139-144.

4. Robinson PM, Muir LT. Wrong-site surgery in orthopaedics. $J$ Bone Joint Surg Br. 2009;91(10):1274-1280.

5. National Health Service Litigation Authority (NHSLA). Reports and Accounts 2010-2011. London; 2011.

6. Institute of Medicine. Crossing the Quality Chasm: A New Health System for the Twenty-first Century. Washington: National Academy Press; 2001.

7. Leape LL. Reporting of adverse events. $N$ Engl J Med. 2002;347(20): 1633-1638.

8. Sheikh A, Hurwitz B. A national database of medical error. $J R$ Soc Med. 1999;92(11):554-555.

9. Panesar SS, Cleary K, Sheikh A. Reflections on the National Patient Safety Agency's database of medical errors. J R Soc Med. 2009;102(7): 256-258.

10. Hickner J, Zafar A, Kuo GM, et al. Field test results of a new ambulatory care medication error and adverse drug event reporting system MEADERS. Ann Fam Med. 2010;8(6):517-525.
11. Panesar SS, Cleary K, Bhandari M, Sheikh A. To cement or not in hip fracture surgery? Lancet. 2009;374(9695):1047-1049.

12. Cresswell KM, Sheikh A. Information technology-based approaches to reducing repeat drug exposure in patients with known drug allergies. J Allergy Clin Immunol. 2008;121(5):1112-1117.

13. Lamont T, Scarpello J. National Patient Safety Agency: combining stories with statistics to minimise harm. BMJ. 2009;339:b4489.

14. National Reporting and Learning Service [homepage on the Internet]. London: NHS. Available from: http://www.nrls.npsa.nhs.uk/. Accessed September 27, 2012.

15. Catchpole K, Bell MD, Johnson S. Safety in anaesthesia: a study of 12,606 reported incidents from the UK National Reporting and Learning System. Anaesthesia. 2008;63(4):340-346.

16. Doll R, Hill AB. Smoking and carcinoma of the lung; preliminary report. Br Med J. 1950;2(4682):739-748.

17. Lee J. Odds ratio or relative risk for cross-sectional data? Int J Epidemiol. 1994;23:201-202.

18. Confirmation of Payment by results Guidance for 2010-2011 [webpage on the Internet]. London: Department of Health; 2010. Available from: http://www.dh.gov.uk/en/Publicationsandstatistics/Publications/ PublicationsPolicyAndGuidance/DH_112284. Accessed September 27, 2012.

19. The Management of Hip Fracture in Adults [webpage on the Internet]. London: National Clinical Guideline Centre. Available from: http:// guidance.nice.org.uk/CG124. Accessed September 27, 2012.

20. Gardner-Thorpe J, Love N, Wrightson J, Walsh S, Keeling N. The value of Modified Early Warning Score (MEWS) in surgical in-patients: a prospective observational study. Ann R Coll Surg Engl. 2006;88(6): 571-575.

21. Malviya A, Martin K, Harper I, et al. Enhanced recovery program for hip and knee replacement reduces death rate. Acta Orthop. 2011;82(5): 577-581.

22. Haynes AB, Weiser TG, Berry WR, et al; Safe Surgery Saves Lives Study Group. A surgical safety checklist to reduce morbidity and mortality in a global population. $N$ Engl J Med. 2009;360(5):491-499.

23. Safety First: Five-year report of the National Confidential Inquiry into Suicide and Homicide by People with Mental Illness [webpage on the Internet]. London: Department of Health; 2001. Available from: http://www.dh.gov.uk/en/Publicationsandstatistics/ Publications/PublicationsPolicyAndGuidance/DH_4006679. Accessed September 27, 2012.

24. Preventing suicide - a toolkit for mental health services [webpage on the Internet]. London: National Patient Safety Agency; 2009. Available from: http://www.nrls.npsa.nhs.uk/resources/?entryid45=65297. Accessed September 27, 2012.

25. Surgical site infection: prevention and treatment of surgical site infection [webpage on the Internet]. London: National Institute for Health and Clinical Excellence; 2008. Available from: http://www.nice.org. uk/Guidance/CG74. Accessed September 27, 2012.

26. Humphreys H. Preventing surgical site infection. Where now? J Hosp Infect. 2009;73(4):316-322.

27. NRLS Quarterly Data Workbook up to June 2010 [webpage on the Internet]. London: National Patient Safety Agency; 2010. Available from: http://www.nrls.npsa.nhs.uk/resources/collections/quarterly-datasummaries/?entryid45=83732. Accessed September 27, 2012.

28. Pham JC, Gianci S, Battles J, et al. Establishing a global learning community for incident-reporting systems. Qual Saf Health Care. 2010;19(5):446-451.

29. Sari AB, Sheldon TA, Cracknell A, Turnbull A. Sensitivity of routine systems for reporting patient safety incidents in an NHS hospital: retrospective patient case note review. BMJ. 2007;334(7584):79.

30. Vincent C, Aylin P, Franklin BD, et al. Is health care getting safer? BMJ. 2008;337:a2426.

31. Memorandum by Andrew Lansley [webpage on the Internet]. London: House of Commons; 2009. Available from: http://www.publications. parliament.uk/pa/cm200809/cmselect/cmhealth/151/151we52.htm. Accessed September 27, 2012. 
32. Lankshear A, Lowson K, Harden J, Lowson P, Saxby RC. Making patients safer: nurses' responses to patient safety alerts. $J A d v$ Nurs 2008;63(6):567-575.

33. Wong DA, Herndon JH, Canale ST, et al. Medical errors in orthopaedics: results of an AAOS member survey. J Bone Joint Surg Am. 2009;91(3): $547-557$.
34. Hospital Episode Statistics online [webpage on the Internet]. Main specialty 2008-2009. Hospital Episode Statistics; 2012. Available from: http://www.hesonline.nhs.uk/Ease/servlet/ContentServer?siteID=1937 \&categoryID=207. Accessed January 10, 2013.

Drug, Healthcare and Patient Safety

\section{Publish your work in this journal}

Drug, Healthcare and Patient Safety is an international, peer-reviewed open-access journal exploring patient safety issues in the healthcare continuum from diagnostic and screening interventions through to treatment, drug therapy and surgery. The journal is characterized by the rapid reporting of reviews, original research, clinical, epidemiological and

\section{Dovepress}

post-marketing surveillance studies, risk management, health literacy and educational programs across all areas of healthcare delivery. The manuscript management system is completely online and includes a very quick and fair peer-review system. Visit http://www.dovepress.com/ testimonials.php to read real quotes from published authors.

Submit your manuscript here: http://www.dovepress.com/drug-healthcare-and-patient-safety-journal 